\title{
Multidecadal change of winter cyclonic activity in the Mediterranean associated with AMO and PDO
}

\author{
Veronika Nikolaevna Maslova ${ }^{*}$, Elena Nikolaevna Voskresenskaya, and Andrey Sergeevich Lubkov \\ Institute of Natural and Technical Systems, Sevastopol, Russian Federation
}

\begin{abstract}
Article history:
Received 29 November 2016

Revised 9 March 2017

Accepted 23 April 2017

Keywords:

Frequency of extratropical cyclones, Storm tracks, $500 \mathrm{hPa}$ geopotential height, $500 \mathrm{hPa}$ vector wind, $850 \mathrm{hPa}$ potential temperature, Total heat flux

Citation:

Maslova, V. N., E. N. Voskresenskaya, and A. S. Lubkov, 2017:

Multidecadal change of winter cyclonic activity in the Mediterranean associated with AMO and PDO. Terr. Atmos. Ocean. Sci., 28, 965-977, doi: 10.3319/TAO.2017.04.23.01
\end{abstract}

\begin{abstract}
The paper is devoted to analysis of the cold half-year (October to March) frequency of cyclones in the Mediterranean-Black Sea region associated with the global processes in the ocean-atmosphere system - the Pacific Decadal Oscillation (PDO) and Atlantic Multidecadal Oscillation (AMO). Firstly, climatic conditions in the North Atlantic-European region during positive and negative phases of these global oscillations were shown using NCEP/NCAR reanalysis data for 1948 - 2016 and data of the NASA GISS Atlas of Exratropical Strom Tracks in 1961 - 1998. Mean monthly values / anomalies (composites) for equal periods of the negative and positive AMO and PDO phases were calculated and compared. The results of the study support the idea that the Pacific and Atlantic influence on the climatic (multidecadal) scale is realized via change of the large-scale fields of the North Atlantic anomalies typical for the interannual scale. Then spatial distribution of the frequency of cyclones in the Mediterranean-Black Sea region was obtained using global NCEP/NCAR reanalysis data sets on $1000 \mathrm{hPa}$ geopotential height in 1948 - 2013. It was shown that during the positive AMO phase, frequency of cyclones in the Mediterranean was higher by absolute values in November to March over the Tyrrhenian and Ionic Seas and lower over the Anatolian peninsula. During the negative PDO phase, frequency of cyclones over the Anatolian peninsula in January to March is significantly higher than in the positive PDO phase.
\end{abstract}

\section{INTRODUCTION}

Cyclonic activity is an integral characteristic of weather-climate anomalies especially in the cold period in midlatitudes. Paths of cyclones (or storm tracks) are the last link in the transmission mechanism of the global climate system influence at the regional level, for example according to Chang and Fu (2002). Earlier (Trigo et al. 1999; Thompson and Wallace 2000) it was shown that the phases of global processes in the ocean-atmosphere system (which can be considered as the climate system) cause specific modes of variability of cyclones.

According to the WMO, climate variability is characterized by the time scale of more than 30 years, in other words interdecadal or multidecadal scale. Nowadays climate models are not designed to reproduce natural decadalmultidecadal variability which accompanies global warming

\footnotetext{
* Corresponding author

E-mail:veronika_maslova@mail.ru
}

trend and is imposed by the climate systems of the Pacific (Trenberth and Fasullo 2013) and Atlantic (Tung and Zhou 2013; Chen and Tung 2014) oceans. For example, Semenov et al. (2014) showed that multidecadal climate variability in the Atlantic and Arctic is responsible for 54\% of global warming and $58 \%$ of the Northern Hemisphere warming. Besides this, Atlantic and Pacific climate variability can be responsible for a "pause" in the global warming also referred to as "hiatus" or "slowdown" (Fyfe et al. 2016) which provokes a lot of debate. That is why, to make projections of clime models more realistic and accurate, it is essential to understand the patterns of climate variability on global and regional scale first.

In spite of the importance of understanding climate variability both on the global and regional level, today it is difficult to obtain statistically reliable results on the multidecadal variability of climatic characteristics including cyclonic activity. It is because the available observational and reanalysis data series are not long enough and generally 
hardly exceed two climate periods (60 years). Nevertheless, despite this obstacle the problem of low-frequency climate variability is of academic interest. For example, Polonskii et al. (2007) and Rimbu et al. (2014) showed that the parameters of cyclones and anticyclones in some Euro-Atlantic regions are characterized by multidecadal variability associated with North Atlantic ocean-atmosphere processes.

Global climate variations of decadal to multidecadal scale were substantiated using proxy records by Wang et al. (2013). Regional climate anomalies in Europe are characterized by multidecadal variability associated with global processes in the ocean-atmosphere system, e.g., as shown by Knight et al. (2006). It is assumed it is true for the variability of cyclones in the Mediterranean-Black Sea region.

The regimes of the Atlantic and Pacific climate systems are characterized by the Atlantic Multidecadal Oscillation (AMO) first described by Schlesinger and Ramankutty (1994), Knight et al. (2006) and Pacific Decadal Oscillation (PDO) first described by Zhang et al. (1997), Mantua et al. (1997) or the Interdecadal Pacific Oscillation (IPO) as it was called by Power et al. (1999). These oscillations are also referred to as climatic signals. They are mostly addressed using indices and positive and negative phases of these indices. Despite the fact that these oscillations are defined by the sea surface temperature (SST) anomalies, they reflect the processes in the ocean-atmosphere systems of the Atlantic and Pacific. Their large (basin-wide and multidecadal) scale is caused by variations of the Subtropical Gyres and Meridional Overturning Circulation. This changes affect sea level pressure (SLP) anomalies due to sensible and latent heat fluxes and lead to the alteration of atmospheric circulation and shift of storm tracks. According to Bosart's (1999) review, oceanic sensible and latent heat fluxes are most crucial at the early stages of cyclone life cycle for a wide spectrum of extratropical cyclones (from the most explosive marine cyclogenesis cases to the weaker frontal waves arising along the quasistationary baroclinic zones). Cyclonic activity also depends on the position and intensity of jet stream flow, which affects energy transport into cyclogenesis via mean flow-eddy interactions. So the storm tracks tend to shift and intensify in the northern periphery of the strong jet stream.

Atmospheric storm tracks shift and intensification on interannual scale can be associated with shifts of ocean fronts such as the Gulf Stream in the North Atlantic (Kwon and Joyce 2013), which is a branch of the North Atlantic Subtropical Gyre and Meridional Overturning Circulation. Dong et al. (2013) highlighted strong ocean-atmosphere interactions associated with the dominant mode of summer storm track variability and an important role of the AMO in the way the ocean influences the atmosphere on decadal timescales. Ting et al. (2014) indicated that warm AMO phase is strongly associated with an SLP pattern that resembles the negative North Atlantic Oscillation (NAO), thus reducing the subtropical jet and storm activity, particularly in winter. Gan and Wu (2015) showed significant interannual coupling between January to March storm track and SST variations in the North Atlantic. According to Lee et al. (2012), North Atlantic storm track activity is characterized by interdecadal regime. Its periods differ in the strength of correlation with the Pacific Decadal Oscillation and North Atlantic Oscillation and coupling with the North Pacific storm track activity. Woollings et al. (2015) showed that on the timescales up to 30 years the NAO is associated with variations in the latitude of the North Atlantic jet and storm track, whereas on the larger timescale with their strength instead.

In spite of the fact that the indices of climate signals are identified by the orthogonal functions (e.g., Enfield and Mestas-Nunez 1999), it is obvious that within the coupled global climate system without rigid walls in the atmosphere, climate signals of the oceans cannot be absolutely independent. Although physical teleconnection mechanisms of the Atlantic and Pacific multidecadal influence and their interaction are still under research now. In general, the commonly recognized mechanism consists in atmospheric bridges which involve mid-latitude anomalies of westerlies and propagation of Rossby waves identified by the jet stream meandering (Wang et al. 2013) in the result of alteration of the atmospheric circulation cells (Alexander et al. 2002). In this way multidecadal processes in the Pacific and Atlantic can induce modulation of the corresponding interannual processes in these oceans such as the NAO first described by Bjerknes (1964), Hurrell (1995) and El Niño-Southern Oscillation (ENSO) first studied by Rasmusson and Carpenter (1982). For example, AMO is referred to as a multidecadal mode of the NAO according to Polonskii (2008). On the other hand, the NAO can be just a manifestation of stochastic variability (Wunsch 1999), and it is still uncertain whether the NAO forces multidecadal variations of AMO (e.g., Latif et al. 2006) or vice versa (e.g., Peings and Magnusdottir 2014). As for the Pacific, El Niño events are more frequent and strong during the positive PDO phase and La Niña events during the negative PDO phase according to Wolter and Timlin (2011).

Knight et al. (2006) showed that HadCM3 climate model simulation reproduces most of the AMO climate impacts derived from short instrumental records. However, Trenberth and Shea (2006) proved that AMO impact was overestimated and in certain periods global warming and $\mathrm{Pa}$ cific (El Niño) influence were more essential. Decadal mode of El Niño, which can be considered as the PDO according to Newman et al. (2003), changed its phase from positive to negative in the mid-1970s and associated with the climate regime shift (Mantua et al. 1997). According to Mantua et al. (1997), the Aleutian Low deepens during the positive PDO phase and due to the Rossby wave propagation atmospheric circulation intensifies in the North Pacific and North Atlantic (Fraedrich et al. 1993; Trenberth et al. 1998). 
Nevertheless, this study does not focus on establishment of teleconnection links (i.e., physical mechanisms) and the direction of causal relationships between climate signals of the Pacific and Atlantic. It focuses on the regional climate anomalies on the basis of an approach consisting in analysis of composite fields for high and low phase periods of climate processes. To understand the complex variability of the Mediterranean-Black Sea regional climate, it is necessary to divide the task and study the contribution of each possible climate process separately first, and then their joint influence.

Taking into account that cyclonic activity is one of important elements of climate system, the aim of this paper is to analyze multidecadal anomalies of cyclones in the Mediterranean-Black Sea region in cold half-year (October to March) associated with global processes in the ocean-atmosphere system: the Atlantic Multidecadal Oscillation and Pacific Decadal Oscillation.

\section{DATA AND METHODS}

To continue our previous research, in this paper we paid attention to multidecadal variability of cyclones in the Mediterranean-Black Sea region using the updated and improved data array of cyclonic characteristics. Cyclones in the Mediterranean-Black Sea region were detected using the methodology by Bardin (1995) applied to the NCEP/NCAR reanalysis data on $6-\mathrm{hr}(0 \mathrm{Z}, 6 \mathrm{Z}, 12 \mathrm{Z}$, and $18 \mathrm{Z}) 1000 \mathrm{hPa}$ geopotential height on a $2.5^{\circ} \times 2.5^{\circ}$ grid for $1948-2013$. At the same time, monthly maps of trajectories of cyclones were taken from the Atlas of Extratropical Storm Tracks based on the SLP fields calculated using the method recommended by the NCEP Reanalysis project, which employs the 12-hr (0Z and 12Z) 500 and $1000 \mathrm{hPa}$ geopotential height fields by the NCEP Reanalysis for the years 1961 - 1999 (the description of methodology is available at http://data. giss.nasa.gov/stormtracks/).

The methodology of cyclones detection (Bardin 1995) used in the research was cross-checked by the IMILAST (Intercomparison of Mid. Latitude Storm Diagnostics) Project (Neu et al. 2013). Its algorithm identifies all local minima of geopotential height field limited by the closed isohypses and calculates a center of each system as a geometrical center of the figure delimited by the first closed contour.

The quality of cyclones identification was checked by comparing with the observational data from the generalized kinematic maps for the period 1951 - 1996. These maps show locations and depths of the centers of cyclones and anticyclones and their trajectories generalizing information from synoptic maps for 3 - 5 days based on actual observations at meteorological stations. So one month is represented by $6-7$ generalized kinematic maps. The available maps cover the period of 46 years (1951 - 1996), thus more than 250 maps per month were analyzed to check the quality of the methodology. The frequency (number of days with cyclones) in the Mediterranean and Black Sea region was counted manually using these maps. As a result, it was shown that time series of the frequency of cyclones obtained using reanalysis and generalized kinematic maps were characterized by strong correlation with a coefficient of 0.9 , as shown by our earlier studies (Voskresenskaya and Maslova 2011).

The indices of the Atlantic Multidecadal Oscillation and Pacific Decadal Oscillation were used as the characteristics of global multidecadal climate variability (Fig. 1). AMO index is an unsmoothed area weighted average of the Kaplan SST V2 over the North Atlantic, $0-70^{\circ} \mathrm{N}$, calculated at NOAA/ESRL/PSD1: http://www.esrl.noaa.gov/psd/ data/timeseries/AMO/.PDO index is derived as the leading PC of monthly SST standardized anomalies in the North Pacific Ocean, poleward of $20^{\circ} \mathrm{N}$ (http://jisao.washington.edu/ pdo/PDO.latest). The monthly mean global average SST anomalies are removed from both indices to separate their variability from the "global warming" signal that may be present in the data.

In order to assess the differences in the anomalies of cyclones frequency corresponding to the AMO and PDO phases, we used a sampling technique referred to as composite analysis. The mean monthly anomalies for the equal periods of the negative and positive phases of these oscillations (called composites) were calculated and compared. This method was also used by other authors, e.g., by Sutton and Dong (2012) for air temperature, precipitation and SLP anomalies in Europe in the warm and transition months
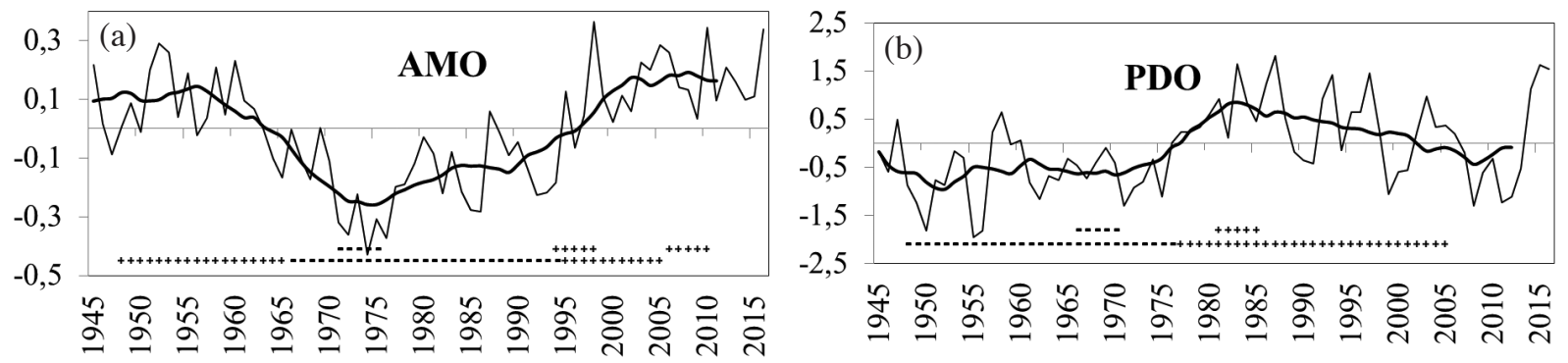

Fig. 1. Annual average of the AMO (a) and PDO (b) indices: unsmoothed and smoothed (bold curve) by the 10-year running mean. Composite periods are indicated by the "+" sign for the positive phases and "-" sign for the negative phases. 
(March to November) averaged over AMO phase periods.

The major problem with this method is separation of climate signals. Composite periods chosen to represent the phases of one variability mode also correspond to different phases of other modes. However, this problem is hard to solve with the short observational record.

Figure 1 shows composite periods used in this study. To identify the most distinctive large-scale climate features in the Atlantic-European region associated with the extremes of the AMO and PDO phases, 5-year periods during the mimimum and maximum of the AMO and PDO phases were chosen to built the composites of the $500 \mathrm{hPa}$ vector wind and geopotential height anomalies, $850 \mathrm{hPa}$ potential temperature anomalies, total (sensitive + latent) heat flux anomalies and storm tracks. Composite period of the minimum AMO index was determined as 1971 - 1975 and the maximum as 2006 - 2010. Storm tracks data were limited by 1998, which is why the 5-year period of the positive AMO index was taken during the index increase as $1994-1998$. The period characterizing the minimum of the PDO index was taken as 1966 - 1970 and the period of the maximum as $1981-1985$.

To illustrate local spatial aspects of cyclone activity in the Mediterranean-Black Sea region for the whole multidecadal phase periods of AMO and PDO, composite maps of the cyclones frequency defined as a sum of cyclonic centers in $2.5^{\circ} \times 2.5^{\circ}$ squares during the equal 29 -year phase periods were obtained for each month of the cold season from October to March. Composite period of the negative AMO phase (AMO-) was determined as 1966 - 1994, and the positive AMO phase (AMO+) - as 1948 - 1965 and 1995 - 2005. Composite period of the negative PDO phase (PDO-) was taken as 1948 - 1976, and the positive phase (PDO+) 1977 $-2005$.

In order to assess significance of the difference between the composites during the chosen AMO and PDO phase periods using Student's $t$-test, monthly time series were created, spatially averaged over the defined areas such as the Mediterranean-Black Sea region, central and northern parts of the North Atlantic, European region, Barents Sea and Middle Asia. Statistical significance of the difference between the 29-year composites was calculated in relation to the interannual standard deviation, and between the 5 -year composites in relation to the standard deviation of the 5-year means for the whole period (1948 - 2016).

Monthly time series and 5-year spatial composites of $500 \mathrm{hPa}$ vector wind, $500 \mathrm{hPa}$ geopotential height anomalies and $850 \mathrm{hPa}$ potential temperature anomalies were obtained using NCEP/NCAR reanalysis data for the 1948 - 2016 period (Kalnay et al. 1996) and interactive tools provided by the NOAA-ESRL Physical Sciences Division, Boulder Colorado at their web-site http://www.esrl.noaa.gov/psd/. Composite schemes of the total heat flux anomalies were also calculated using NCEP/NCAR reanalysis data and the
1948 - 2016 climate average.

Composites of the vector wind at $500 \mathrm{hPa}$ were involved in order to characterize the zonal flow, in other words to identify potential location and intensity of tropospheric jet stream, since it is closely associated with storm tracks. Position of tropospheric jet stream is identified by the maximum wind vector at the level of the jet stream (here, $500 \mathrm{hPa}$ ). As for the $500 \mathrm{hPa}$ geopotential height anomalies (in relation to the 1948 - 2016 climate average), they reflect the character of the large-scale atmosheric circulation. Potential temperature anomalies were analyzed to describe the meridional temperature gradient which characterizes baroclinicity in condition of static stability of the atmosphere and determines dynamic instability of the zonal flow. Meridional temperature gradient causes thermal wind characterized by the negative anomalies to the left of its direction. To address heat exchange processes in the ocean-atmosphere system, composite schemes of the total (sum of latent and sensible) heat flux anomalies were obtained. So the impacts of AMO and PDO on cyclones activity were examined via zonal flow, circulation and heat flux variability, which are the parameters reflecting both upperlevel and lower-level processes in the ocean-atmosphere system associated with cyclone activity.

\section{RESULTS AND DISCUSSION}

\subsection{AMO Impact on the Atlantic-European Region: Large-Scale View}

Interdecadal variability of cyclonic activity in the Atlantic-European region associated with the Atlantic Multidecadal Oscillation was demonstrated by Polonskii et al. (2007) on the example of linear trends of the frequency and intensity of cyclones in 1952 - 2000. The authors point out that in 1960s - 1990s (when AMO index increased) there was a statistically significant increase in frequency and intensity of cyclones in the cold half-year in the subpolar latitudes of the North Atlantic (between 55 and $75^{\circ} \mathrm{N}$ ) and in the south-eastern part of the Mediterranean region, while in the mid-latitudes of the North Atlantic (between 35 and $55^{\circ} \mathrm{N}$ ) and over the most of Europe frequency (but not intensity) of cyclones decreased.

Later Polonskii (2008) developed a mechanism of AMO influence on European region involving trajectories of cyclones (storm tracks). It was assumed that AMO as well as NAO is characterized by the shift of the Atlantic storm tracks but with the opposite sign, because the greatest influence on the regional climatic anomalies is induced not by the pressure gradient between the centers of action of the atmosphere but their location. During the positive NAO phase the Icelandic Low and Azores High shift to the northeast, and during the positive AMO phase to the southwest. One of the tasks of this study was to analyze regional features of winter cyclonic activity in the Mediterranean-Black Sea associated with AMO within the abovementioned scheme 
on the example of January, but first, it was necessary to analyze large-scale processes in the ocean-atmosphere over the Atlantic-European region.

Spatial composites of the mean $500 \mathrm{hPa}$ vector wind and geopotential height anomalies, $850 \mathrm{hPa}$ potential temperature anomalies, $500 \mathrm{hPa}$ vector wind and storm tracks were obtained to assess the differences in these characteristics between the 5-year periods of the minimum (1971 1975) and maximum (2006 - 2010) or transition to the maximum (1994 - 1998) AMO index as shown in Fig. 2. Further anomalies providing significant (at the 80 - 99\% confidence level) differences of composites between the AMO phase periods are described.

During the negative AMO phase (Fig. 2, AMO- column) $500 \mathrm{hPa}$ zonal flow over the North Atlantic exceeded $26 \mathrm{~m} \mathrm{~s}^{-1}$. As for the European region, it was higher over the Northern Europe than over the Southern Europe and the Mediterranean-Black Sea region (Fig. 2a). During the positive AMO phase (Fig. 2, AMO+ column), zonal flow over the North Atlantic was weaker $\left(22 \mathrm{~m} \mathrm{~s}^{-1}\right)$, and although its axis was shifted to the north on the eastern coast, the zonal flow over Europe was the strongest in the eastern Mediterranean (Fig. 2b). Differences of zonal wind velocity composites between the AMO phases are significant at the $99 \%$ confidence level over the western part of the North Atlantic and at the $95 \%$ over the Northern Europe.

The composite field of the $500 \mathrm{hPa}$ geopotential height anomalies indicates that during the negative AMO phase (Fig. 2c) there were strong centers of atmospheric action over the North Atlantic shifted to the south-west. Negative anomalies of the Islandic Low exceeded $-100 \mathrm{~m}$ at the $99 \%$ level of statistical significance of the difference between the composites, and over the Azores High $+40 \mathrm{~m}$ at the $80 \%$ confidence level. This pattern resembles the positive NAO phase. There were also strong significant (exceeding $+80 \mathrm{~m}$, $80 \%$ confidence level) positive geopotential height anomalies over the entire Europe and further to the east negative anomalies which had the same absolute value significant at the $99 \%$ confidence level. Such spatial structure of geopotential height anomalies resembles the East Atlantic and Northern Asian (Siberian) atmospheric patterns (Barnston and Livezey 1987). Three centers with the most intense geopotential height anomalies forming the west-east seesaw can be marked over the Labrador Peninsula (shifted Islandic Low), European region and Middle Asia with the same sign of anomalies over the first and last centers and the opposite sign over the second centre.

As for the positive AMO phase (Fig. 2d), it was characterized by the low gradient field of the weak (+20 m maximum in the Azores High, 80\% confidence level) mainly positive geopotential height anomalies over the North Atlantic during the chosen (2006 - 2010) composite period. The strongest center of action (positive anomalies exceeding $+60 \mathrm{~m}, 99 \%$ confidence level) was over the Barents and
Kara Seas. This agrees with the results by Semenov et al. $(2009,2014)$ about the importance of the Arctic processes [anomalous heat fluxes (Figs. $2 \mathrm{~g}, \mathrm{~h}$ ) and Barents Sea Inflow] in the multidecadal variability in the North Atlantic.

General structure of the composite field of the $850 \mathrm{hPa}$ potential temperature anomalies during both AMO phases (Figs. 2e, f) corresponds to the $500 \mathrm{hPa}$ geopotential height anomalies. During the negative AMO phase (Fig. 2e), the strongest negative anomalies lower than -3 K (99\% confidence level) were over the Labrador Peninsula and Middle Asia, and the highest positive anomalies exceeding $+2 \mathrm{~K}$ ( $99 \%$ confidence level) were over the Northern Europe and western coast of the tropical North Atlantic. So there was strong meridional potential temperature gradient over the central North Atlantic indicating the strong thermal wind in this area. During the positive AMO phase the center of the strongest positive anomalies exceeding 3 - 4 K (90\% confidence level) were over the Barents Sea spreading to the North Atlantic over the area to the north of Island (Fig. 2f).

In agreement with displacement of the geopotential height and potential temperature anomalies over the western coast of North Atlantic, the most significant (99\% confidence level) differences of the total heat flux anomalies between the AMO phases were found in the Labrador Sea and in the area of the Gulf Stream, but they had opposite sign in these centers (Figs. 2g, h). During the negative AMO phase, there were positive heat flux anomalies in the Labrador Sea and negative anomalies in the Gulf Stream (Fig. 2g), and during the positive AMO phase there were anomalies of the opposite sign in these regions (Fig. 2h).

The resulting spatial composites of the total storm tracks associated with the AMO phases (Figs. 2i,j) agree well with the described features of zonal flow, circulation and thermal characteristics. During the negative AMO phase, concentration of the North Atlantic storm tracks (Fig. 2i) was the densest along the axis Labrador Peninsula-Island-Barents Sea. In Europe, including Mediterranean-Black Sea region, cyclonic activity was low. During the positive AMO phase the North Atlantic storm tracks were concentrated along a broader band, in the south reaching the north of Florida and covering Scandinavia (Fig. 2j). Cyclonic activity in the MediterraneanBlack Sea region was higher than in the previous case.

The analysis showed that the described spatial character of composite fields in January is typical for the months of the cold half-year from November to March.

To demonstrate the quantitative characteristic of AMO impact on regional cyclone activity, the spatially averaged zonal flows and storm numbers in the Mediterranean-Black Sea region $\left(30-45^{\circ} \mathrm{N}, 10^{\circ} \mathrm{W}-45^{\circ} \mathrm{E}\right)$ were calculated on the basis of the obtained composites. It was found that during the negative AMO phase in 1971 - 1975 the number of storm tracks in January in the region was 15 and the corresponding mean zonal flow was $9.4 \mathrm{~m} \mathrm{~s}^{-1}$. As for the positive AMO phase in 1994 - 1998, the values were higher: 23 
(a)

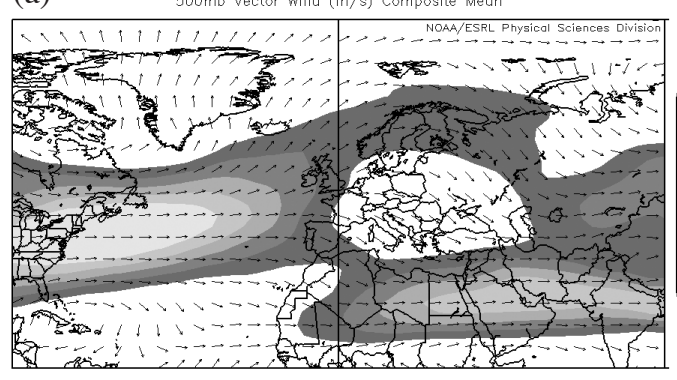

(c)

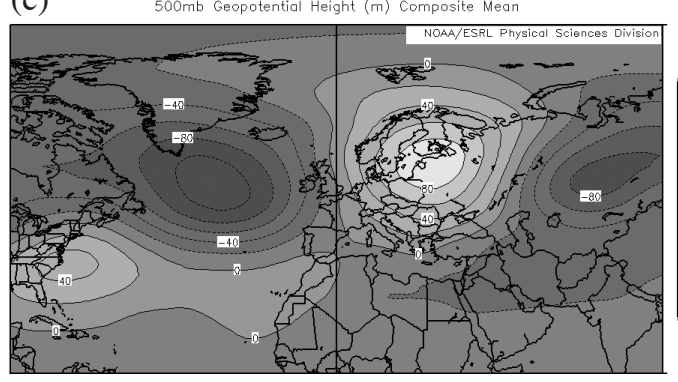

Jan: 1971 to 1975 minus 1948 to 2016

(c)

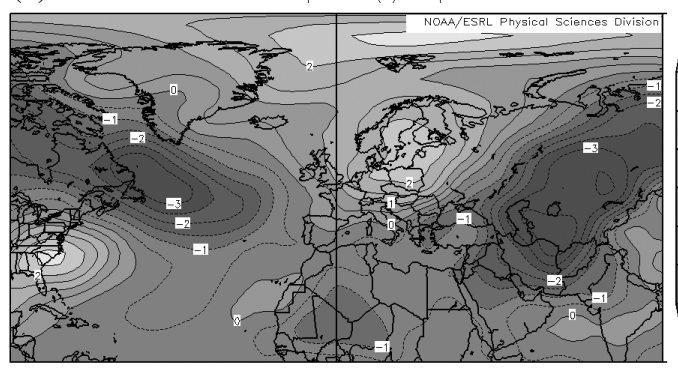

(g)

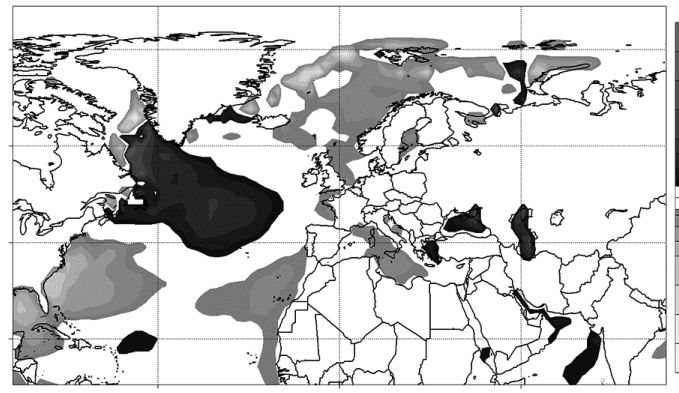

(i)

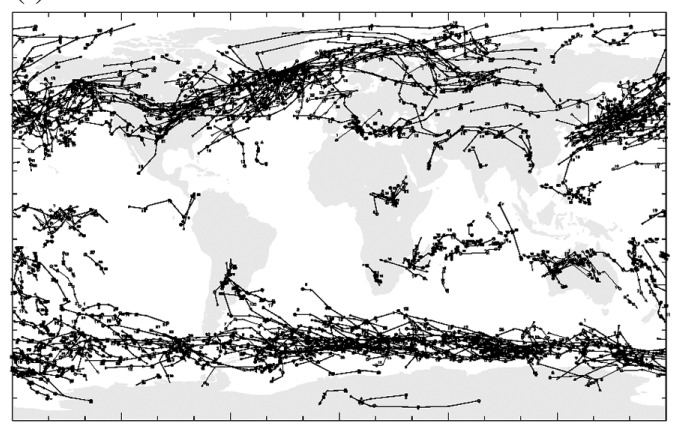

(b)

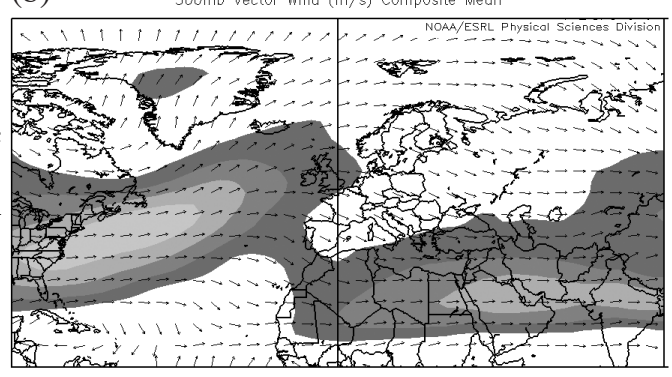

(d)

Jan: 2006 to 2010

500mb Geopotential Height (m) Composite Meo

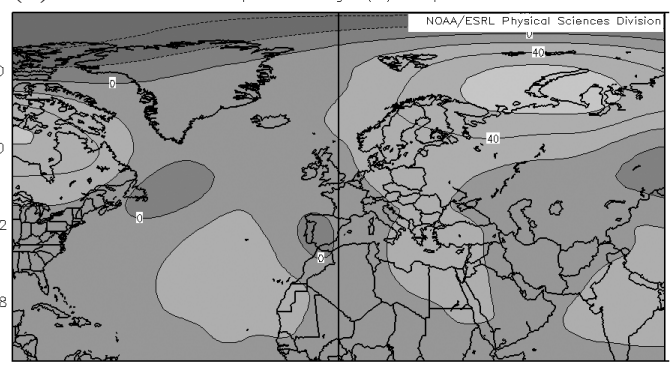

(f)

1948 to 2016

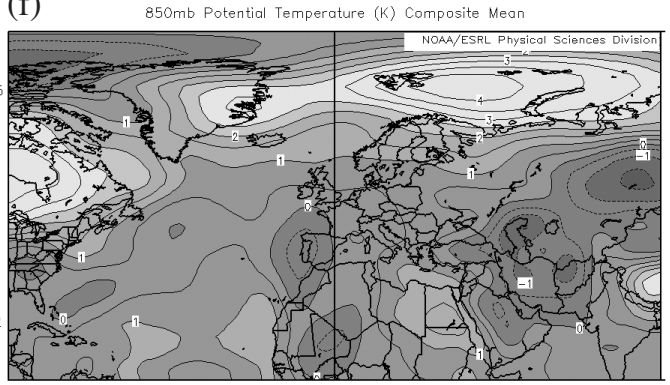

(h)

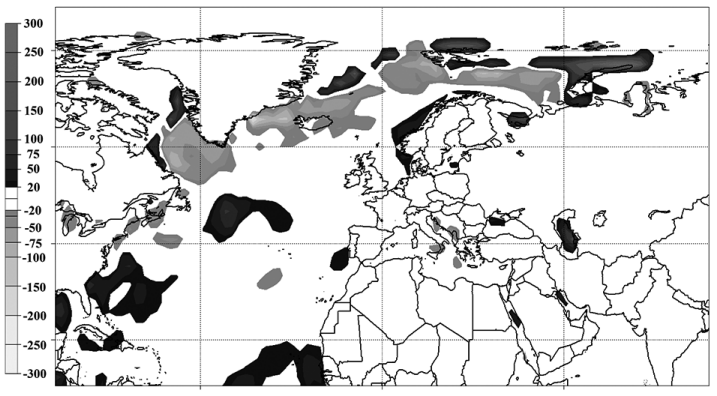

(j)

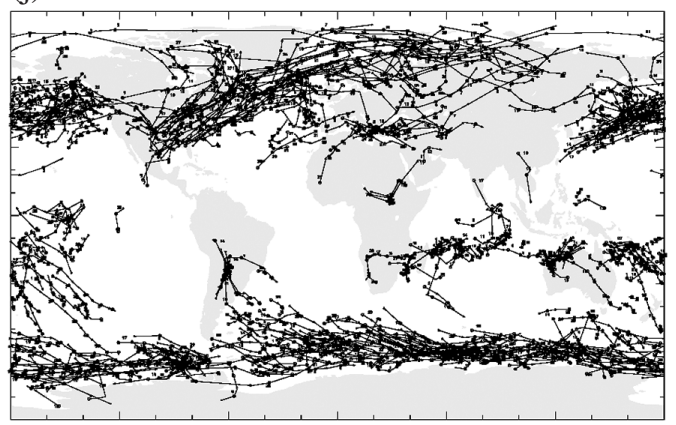

Fig. 2. 5-year composites in January for the minimum AMO index in 1971 - 1975 (AMO- column) and maximum AMO index in 2006 - 2010 and 1994 - 1998 for the storm tracks (AMO+ column): (a) and (b) represent mean $500 \mathrm{hPa}$ vector wind; (c) and (d): $500 \mathrm{hPa}$ geopotential height anomalies; (e) and (f): $850 \mathrm{hPa}$ potential temperature anomalies (K); (g) and (h): total (sum of sensible and latent) heat flux anomalies (in relation to the 1948 - 2016 climate average); (i) and (j): total storm tracks. 
storm tracks and $10.9 \mathrm{~m} \mathrm{~s}^{-1}$. The difference between these spatially averaged composites during the AMO phase periods is significant at the $90 \%$ confidence level for storm track numbers and for the mean zonal flow, too.

Consequently, on the example of January it was shown that the AMO is characterized by the north-south dispersion of winter storm tracks over the North Atlantic-European region which is supported by the $500 \mathrm{hPa}$ vector wind, geopotential height, and $850 \mathrm{hPa}$ potential temperature anomalies. During the negative AMO phase, storm tracks are densely concentrated over the north-eastern part of the North Atlantic and during the positive phase they spread southward accompanying the intensification of cyclonic activity in the Mediterranean-Black Sea region. It was suggested that the fields of climate anomalies for the AMO phases corresponds to the atmospheric patterns of interannual variability - North Atlantic, East Atlantic Oscillations and Northern Asian (Siberian) pattern.

\subsection{AMO Impact on the Mediterranean-Black Sea Region: Local Aspects}

Correlation analysis of monthly frequency of cyclones in the Mediterranean-Black Sea region with the unsmoothed AMO index was carried out separately for the intervals of positive / negative phases of the AMO and periods of increase / decrease of the index. The most significant monthly correlation coefficients $(+0.3$ to +0.58$)$ were found during the cold half-year for all the time intervals. The positive sign of correlation further confirms that cyclonic activity in the Mediterranean-Black Sea is generally higher during the positive AMO phase than during the negative phase.

To illustrate spatial variability of cyclonic activity in different AMO phases, frequency of cyclones (defined as the sum of cyclonic centers in $2.5^{\circ} \times 2.5^{\circ}$ squares) during the equal time intervals of the negative $(1966$ - 1994) and positive (1948 - 1965 and 1995 - 2005) AMO phases and the difference between the phases were calculated and mapped for each month of the cold season from October to March. The results for January are shown in Fig. 3 as an example. It shows that during both AMO phases, high frequency of cyclones was concentrated along the line connecting the Tyrrhenian Sea, Crete and Cyprus with the maximum in the northern part of the Tyrrhenian Sea. Figure 3c illustrates that during the positive AMO phase the frequency of cyclones was higher in the spots located in the Central Mediterranean (south-eastern part of the Tyrrhenian Sea, Ionic Sea, and Greece) and lower in the Eastern Mediterranean, especially over the Anatolian Peninsula. Analysis showed that during the positive AMO phase the frequency of cyclones was higher (than in the negative phase) by absolute values in the months from November to March of the cold half-year over the Tyrrhenian and Ionic Seas and lower over the Anatolian Peninsula.

\subsection{PDO Impact on the Atlantic-European Region: Large-Scale View}

It was shown by Bardin and Voskresenskaya (2007) that the Pacific Decadal Oscillation influence on the Atlantic-European region is associated with a change (modulation) of the NAO on the multidecadal scale. Positive PDO phase is accompanied by the strengthening NAO and as a consequence by intensification of the zonal circulation in the high latitudes. Negative PDO phase corresponds to the opposite anomaly, i.e., weakening NAO and zonal circulation. The results of Wang et al. (2006) indirectly evidence that the NAO intensified simultaneously with the growth of the PDO index. It was specifically shown that from January to March in 1958 - 2001 (during the increase of the PDO index) there was a positive trend of the activity of intense cyclones in the high latitudes of the North Atlantic and Northern Europe and a negative one in the mid-latitudes. The authors attribute this feature to the shift of the average position of the Atlantic storm tracks by about $180 \mathrm{~km}$ to the north. Thus the impact of the PDO on the position of the Atlantic storm tracks has been shown indirectly in the scientific literature, but for the Mediterranean-Black Sea region such research has not been carried out yet. This is why this task was also included in our research.

To support the mechanism of the PDO influence via the NAO suggested by Bardin and Voskresenskaya (2007), spatial composites of the $500 \mathrm{hPa}$ mean vector wind and geopotential height anomalies, $850 \mathrm{hPa}$ potential temperature anomalies, total heat flux anomalies and storm tracks in the Atlantic-European region in winter corresponding to the 5-year periods of the minimum (1966 - 1970) and maximum (1981 - 1985) PDO index were obtained for the each month from October to March, as shown in Fig. 4 on the example of January. Further we only describe anomalies providing significant (at the 80 - 99\% confidence level) differences of composites between the PDO phase periods .

As one can see in Figs. 4a, b, the maximum velocity of the mean $500 \mathrm{hPa}$ zonal flow over the North Atlantic was equal (exceeding $26 \mathrm{~m} \mathrm{~s}^{-1}$ ) for both PDO phases, but during the positive PDO phase the stream orientation was more meridional, and over the Central and partly Northern Europe zonal flow was more intense by $4-8 \mathrm{~m} \mathrm{~s}^{-1}$ (Fig. 4b) than in the negative phase (Fig. 4a). Differences of zonal wind velocity composites between the PDO phases are significant at the $99 \%$ confidence level over the eastern part of North Atlantic and over the Central Europe as well.

The field of the $500 \mathrm{hPa}$ geopotential height anomalies in the centers of atmospheric action over the North Atlantic was characterized by the see-saw anomalies between the positive and negative PDO phases significant at the $99 \%$ confidence level. During the negative PDO phase there were negative anomalies (lower than $-80 \mathrm{~m}$ ) in the Azores High with the extension and sub-center over the Mediterranean 
and there were positive anomalies (higher $+120 \mathrm{~m}$ ) in the Islandic Low shifted to the west (Fig. 4c). So the centers of action were weak and NAO index was negative. As for the positive PDO phase, there were the opposite conditions: deep Islandic Low $(-80 \mathrm{~m})$ dislocated to Scandinavia, strong Azores High (+80 m) shifted to the north-east (Fig. 4d), i.e., NAO index was positive.

The general structure of the $850 \mathrm{hPa}$ potential temperature anomalies during PDO phases (Figs. 4e, f) resembles $500 \mathrm{hPa}$ geopotential height anomalies. During the negative PDO phase (Fig. 4e) the values were lower than -2 K (99\% confidence level) in the Azores High (neighboring the area of positive anomalies over west Africa) and higher than +3 $\mathrm{K}$ (99\% confidence level) in the Island Low, while over the Central Europe they reached -3 K (95\% confidence level). During the positive PDO phase the sign of anomalies in the centers over the North Atlantic was the opposite at the 99\% confidence level: higher than $+1 \mathrm{~K}$ in the Azores High and lower than $-3 \mathrm{~K}$ in the Islandic Low (Fig. 4f). So, the described conditions favored instability and thermal wind displacement in the northern latitudes of the North Atlantic during the positive PDO phase and in the southern latitudes during the negative PDO phase.

The most significant differences in the total heat flux anomalies were in the center of the North Atlantic in the area of the Azores High: positive during the negative PDO phase (Fig. 4g) and negative during the positive phase (Fig. 4h) at the $99 \%$ confidence level. There were also significant but opposite differences in the North Atlantic to the southernmost coast of Greenland ( $90 \%$ confidence level) and in the area of the Gulf Stream (80\% confidence level).

Composite schemes of storm tracks confirm the features described above. During the negative PDO phase (Fig. 4i), there were several branches of the North Atlantic storm tracks with a denser central one. Over the European region a cluster of storm tracks directed approximately from

(a)

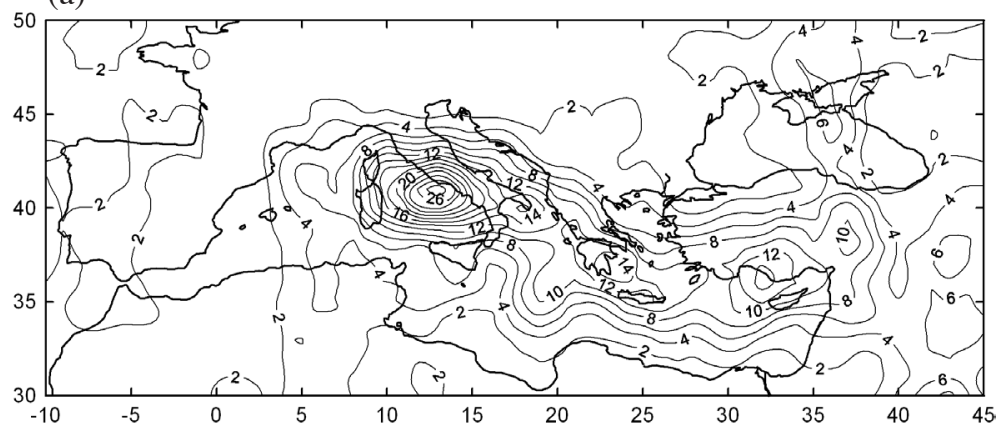

(b)

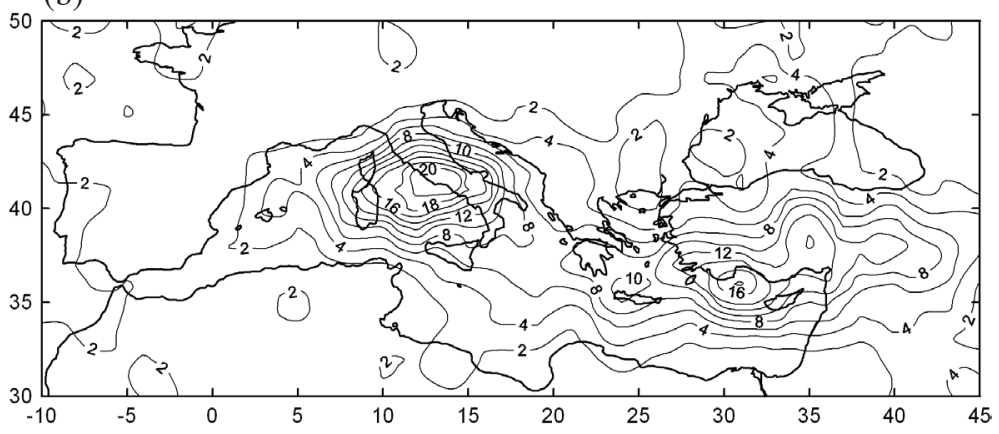

(c)

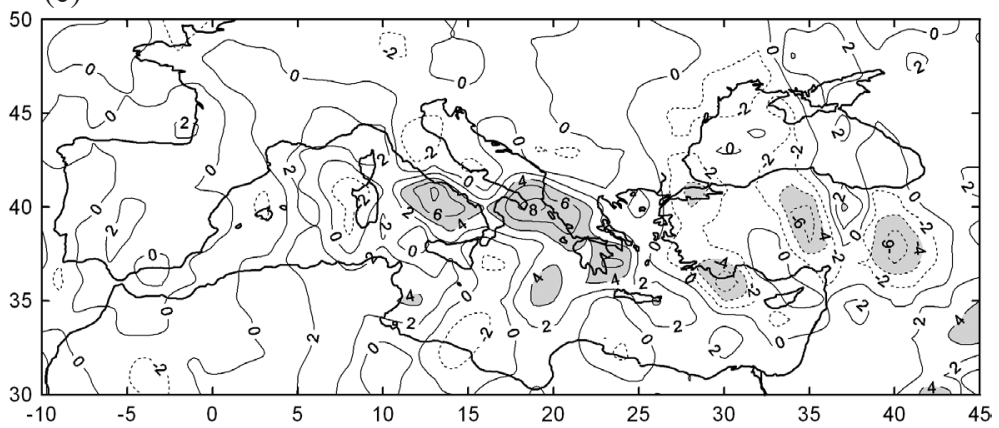

Fig. 3. Frequency of cyclones in January during the (a) positive (1948 - 1965 and 1995 - 2005) and (b) negative (1966 - 1994) AMO phases; (c) is the difference: (a) - (b). 
(a)

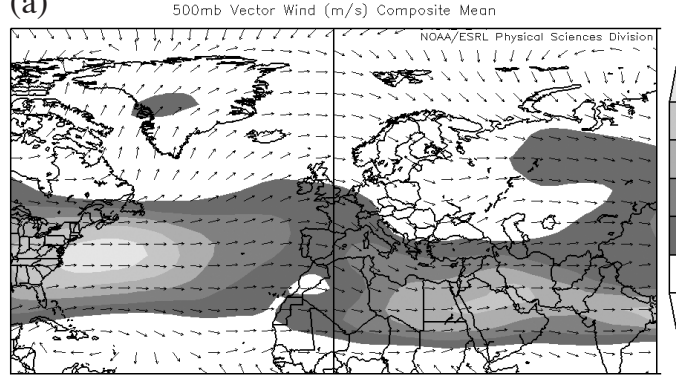

(c)

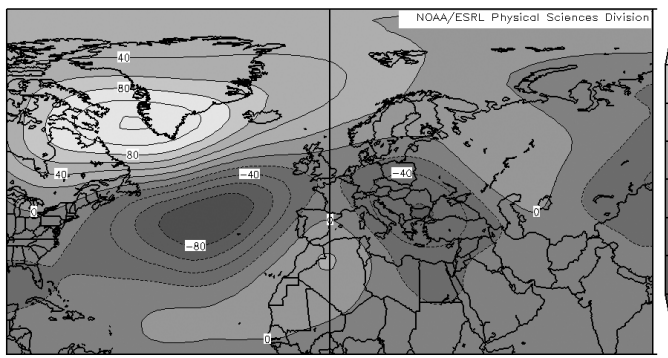

Jan: 1966 to 1970 minus 1948 to 2016

(e)

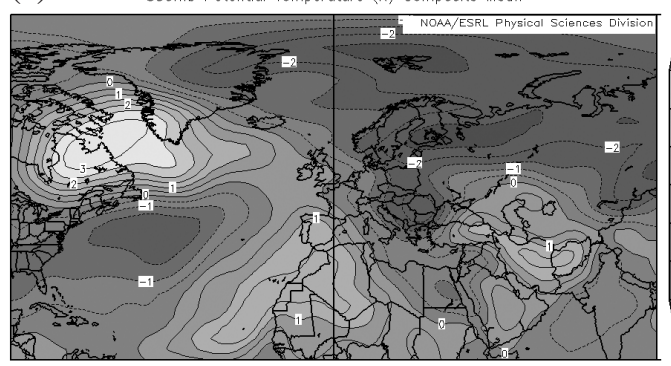

(g)

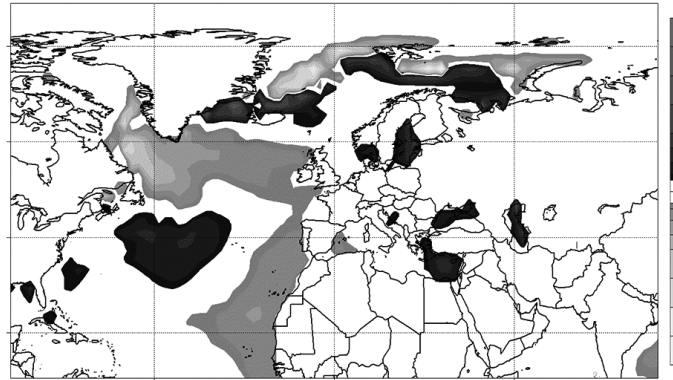

(i)

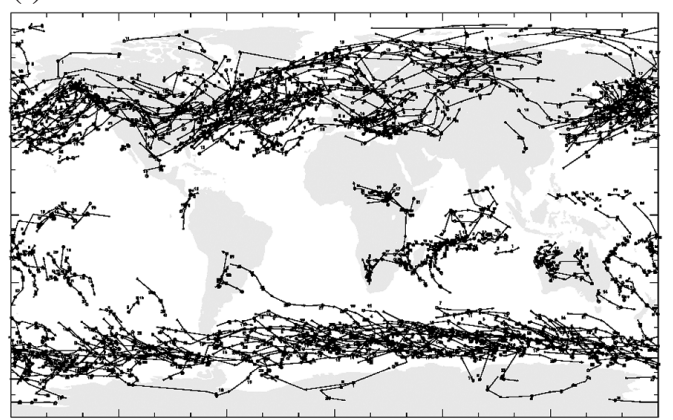

(b) NCEP/NCAR Reanolysis

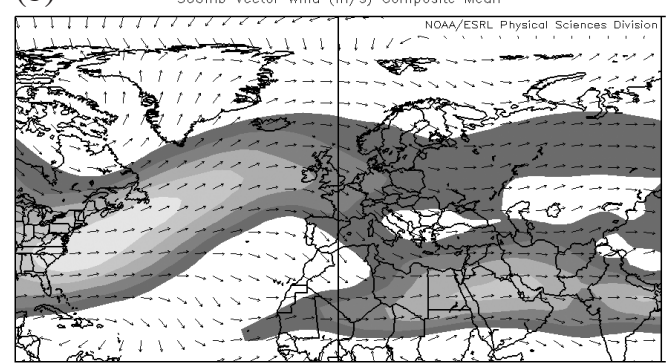

(d)

Jan: 1981 to 1985

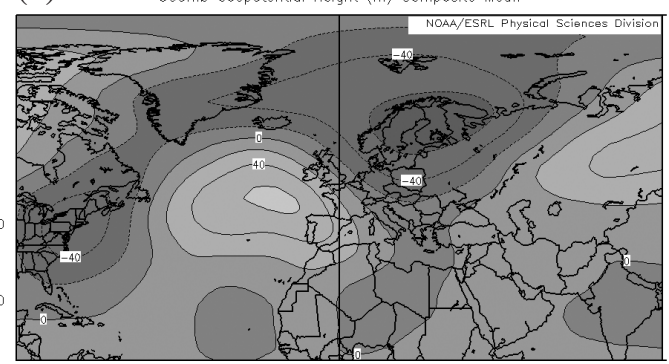

1981 to 1985 minus 1948 to 2010

(f)

NCEP/NCAR Reanolysis
850mb Potential Temperature (K) Composite Mean

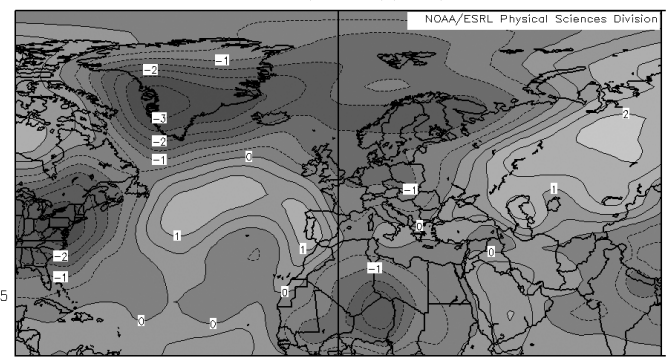

(h)

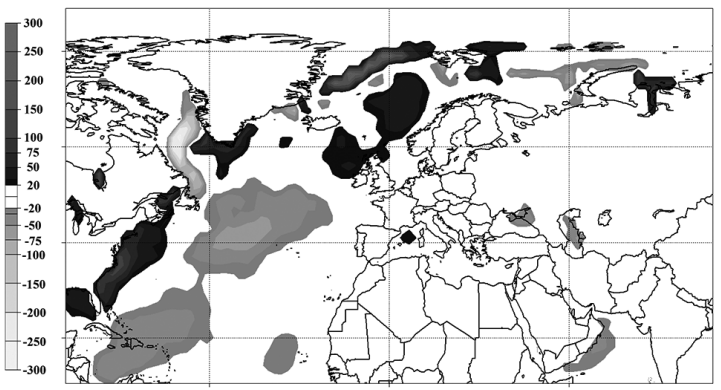

(j)

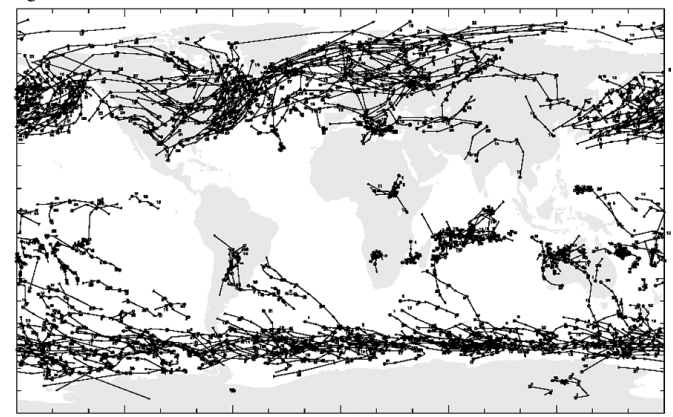

Fig. 4. 5-year composites in January for the minimum PDO index in 1966 - 1970 (PDO- column) and maximum PDO index in 1981 - 1985 (PDO+ column): (a) and (b) represent mean $500 \mathrm{hPa}$ vector wind; (c) and (d): $500 \mathrm{hPa}$ geopotential height anomalies; (e) and (f): $850 \mathrm{hPa}$ potential temperature anomalies $(\mathrm{K})$; (g) and (h): total (sum of sensible and latent) heat flux anomalies (in relation to the 1948 - 2016 climate average); (i) and (j): total storm tracks. 
Baltic to the Black Sea can be distinguished. These are the so called "diving" cyclones moving southward or southeastward, and they are a typical for the meridional type of atmospheric circulation. In the Mediterranean, cyclonic activity is high. During the positive PDO phase, the North Atlantic storm tracks are dense along the American coast, Greenland and Island (Fig. 4j). Cyclonic activity is high in the Northern Europe and low in the Mediterranean. In general, the positive PDO phase is characterized by fewer meridional storm tracks over the European region than the negative one.

The described spatial character of composite fields in January is typical for the months of the cold half-year from November to March.

As for the Mediterranean-Black Sea region $\left(30-45^{\circ} \mathrm{N}\right.$, $10^{\circ} \mathrm{W}-45^{\circ} \mathrm{E}$ ), on the basis of composites in Fig. 4 it was obtained that during the negative PDO phase in 1966 - 1970 the number of storm tracks in January in the region reached 28 and the corresponding spatially averaged zonal flow was $12.5 \mathrm{~m} \mathrm{~s}^{-1}$. As for the positive PDO phase in $1981-1985$, the values were much lower: 16 storm tracks and $10.5 \mathrm{~m} \mathrm{~s}^{-1}$. The difference between the composites during these PDO phase periods is significant at the $99 \%$ confidence level for the storm track numbers and at the $95 \%$ level for the mean zonal flow.

To sum up, the obtained results support the idea that PDO influence can be transmitted in winter to the Atlantic-European region, including the Mediterranean and the Black Sea, indirectly by the mechanism involving the shift of the North Atlantic storm tracks.

\subsection{PDO Impact on the Mediterranean-Black Sea Region: Local Aspects}

Spatial analysis of cyclonic activity in the Mediterranean-Black Sea region during different PDO phases was carried out by analogy with the analysis for the AMO. During the equal time intervals of the negative (1948 - 1976) and positive (1977 - 2005) PDO phases, frequency of cyclones (the sum of the centers of cyclones) and the difference between the two phases were mapped for the months from October to March. Figure 5 shows the frequency of cyclones in January as an example. It demonstrates that during the PDO phases in the Western Mediterranean there were differences in the value of frequency of cyclones over Italy and Tyrrhenian Sea and also in the spatial distribution of the zones with high cyclonic frequency in the Eastern Mediterranean and Anatolian Peninsula.

During the negative PDO phase in January (Fig. 5a) like in all months from November to March, the zone with high frequency of cyclones shifted in the meridional direction by $3-5^{\circ}$ from the northwestern vicinity of Cyprus (where it was located during positive PDO phase - Fig. 5b) to the Anatolian peninsula up to the southern slope of Pontic Mountains, and it noticeably intensified in January to
March. Taking into account the mean detected radius of a cyclone of about $500 \mathrm{~km}$, the Black Sea experienced conditions of the cold sector of cyclones in these months more often during the negative PDO phase.

To assess the quantitive differences of cyclonic activity, monthly time series of the frequency of cyclones were obtained and analyzed. The analysis showed that during the negative PDO phase, frequency of cyclones over the Anatolian peninsula in January-March is up to two times greater (at the $95 \%$ significance level) than in the positive PDO phase.

So, the analysis showed that cyclone activity in the Mediterranean-Black Sea region tends to enhance during the positive AMO phases and the negative PDO phases, but PDO is characterized by more significant regional manifestations than the AMO. This agrees with the results shown by Enfield and Mestas-Nunez (1999) that the PDO is a mode of higher degree (third) than the AMO (fourth) in decomposition of the global SST field on the empirical orthogonal functions. Besides that, in these two phases (AMO+ and PDO-) the major circulation feature is location and intensity of zonal flow which is further south during the negative PDO phase than the positive AMO phases. In connection with this meridional displacement of the zonal flow from the Atlantic into the Mediterranean (Figs. 2b and 4a), there are more substantial regional responses in cyclonic activity in the MediterraneanBlack Sea region during the negative PDO phase than during the positive AMO phase (Figs. 2h and 4g, 3a, c and 5a, c).

\section{CONCLUSION}

Cold half-year cyclonic activity in the MediterraneanBlack Sea region associated with the Atlantic Multidecadal Oscillation and Pacific Decadal Oscillation was studied using composite analysis of the $500 \mathrm{hPa}$ vector wind and geopotential height anomalies, $850 \mathrm{hPa}$ potential temperature anomalies, total heat flux anomalies and storm tracks in the Atlantic-European region and spatial frequency of cyclones in the Mediterranean-Black Sea region.

It was demonstrated that the fields of climate anomalies for the AMO phases correspond to the atmospheric patterns of interannual variability - the North Atlantic, East Atlantic Oscillations and Northern Asian (Siberian) pattern. It was shown that the AMO is characterized by the north-south shift of winter storm tracks over the North Atlantic-European region. During the negative AMO phase, storm tracks are densely concentrated over the north-eastern part of the North Atlantic and during the positive phase they spread more southward. In the regional aspect of the Mediterranean and Black Sea the frequency of cyclones was higher by absolute values in the positive AMO phase than in the negative one in November to March over the Tyrrhenian and Ionic Seas and lower over the Anatolian Peninsula.

The results of this paper support that the PDO influence can be transmitted to the Atlantic-European region indirectly 


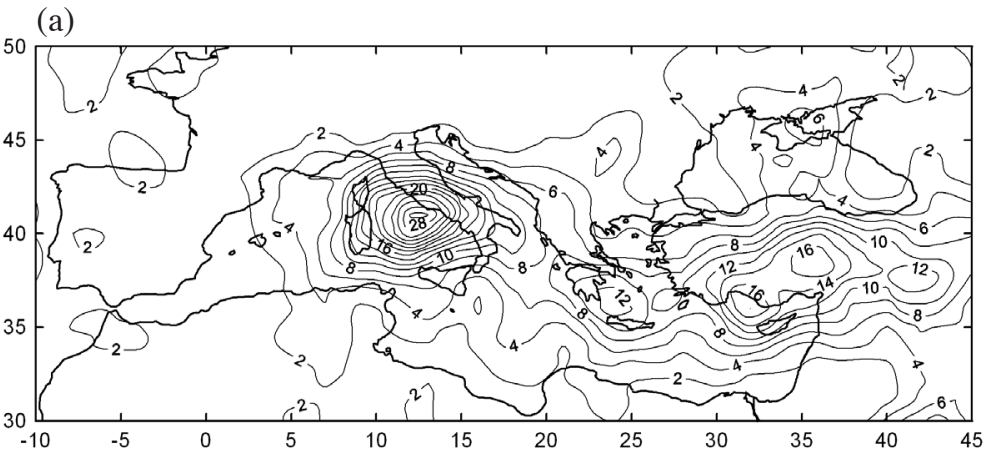

(b)

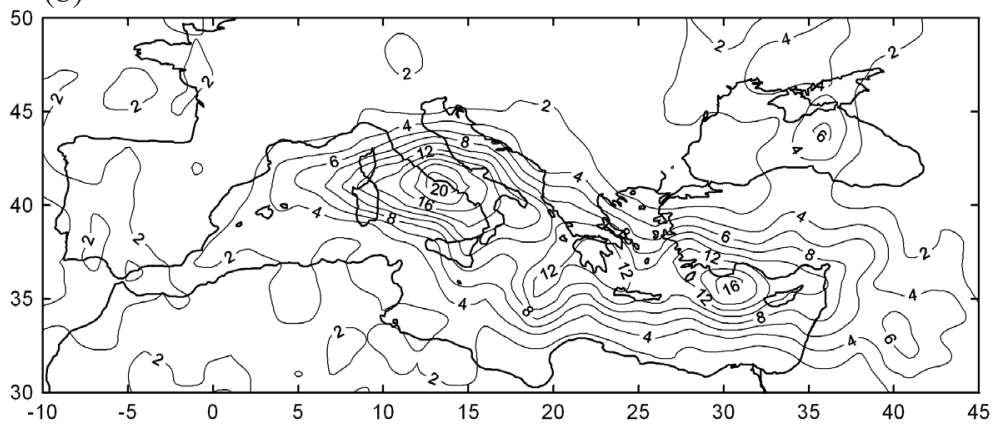

(c)

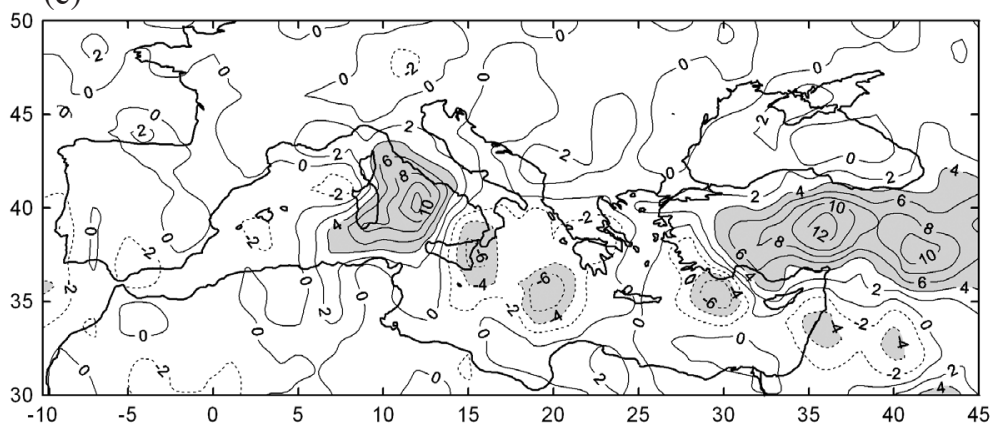

Fig. 5. Frequency of cyclones in January during the (a) negative (1948 - 1976) and (b) positive (1977 - 2005) PDO phases; (c) is the difference: (a) - (b).

via the North Atlantic Oscillation by the mechanism involving the shift of the North Atlantic storm tracks. The analysis showed that in the Mediterranean-Black Sea region in the negative PDO phase frequency of cyclones over the Anatolian peninsula in January to March is up to two times higher (at the 95\% significance level) than in the positive PDO phase and the Black Sea experiences conditions of the cold sector of cyclones more often than in the positive PDO phase.

In this study, impacts of AMO and PDO on cyclone activity in the Mediterranean are examined separately. Cyclone activity tends to enhance during the positive AMO phases and the negative PDO phases. In these two phases, zonal flow from the Atlantic into the Mediterranean is characterized by meridional displacement. It is further south during the negative PDO phase and causes more significant regional manifestations in cyclonic activity in the MediterraneanBlack Sea region than during the positive AMO phase.

To conclude, the paper reveals the possible regional anomalies coinciding with the high and low phase periods of the climatic processes which are actually the result of interaction between the multidecadal and interannual processes independent of the type and direction of their causal relationships. The interaction and joint influence of climate signals will be the subject of our future study.

Acknowledgements The authors appreciate the valuable comments of two anonymous referees for the enriching contribution into our research. We also thank Valentina Naumova, director of Sevastopol Hydrometeorological Observatory, and Alexander Yurovsky, senior researcher of Marine Hydrophysical Institute.

\section{REFERENCES}

Alexander, M. A., I. Bladé, M. Newman, J. R. Lanzante, N.C. Lau, and J. D. Scott, 2002: The atmospheric bridge: 
The influence of ENSO teleconnections on air-sea interaction over the global oceans. J. Climate, 15, 22052231, doi: 10.1175/1520-0442(2002)015<2205:tabtio> 2.0.co;2. [Link]

Bardin, M. Y., 1995: Variability of cyclonic characteristics in the middle troposphere of the North hemisphere midlatitudes. Meteorol. Hydrol., 11, 24-37.

Bardin, M. Y. and E. N. Voskresenskaya, 2007: Pacific Decadal Oscillation and European climatic anomalies. Phys. Oceanogr., 17, 200-208, doi: 10.1007/s11110007-0016-6. [Link]

Barnston, A. G. and R. E. Livezey, 1987: Classification, seasonality and persistence of low-frequency atmospheric circulation patterns. Mon. Weather Rev., 115, 1083-1126, doi: 10.1175/1520-0493(1987)115<1083: CSAPOL $>2.0 . \mathrm{CO} ; 2$. [Link]

Bjerknes, J., 1964: Atlantic air-sea interaction. Adv. Geophys., 10, 1-82, doi: 10.1016/s0065-2687(08)60005-9. [Link]

Bosart, L. F., 1999: Observed Cyclone Life Cycles. In: Shapiro, M. A. and S. Grønås (Eds.), The Life Cycles of Extratropical Cyclones, American Meteorological Society, Boston, MA, 187-213, doi: 10.1007/978-1935704-09-6_15 . [Link]

Chang, E. K. M. and Y. Fu, 2002: Interdecadal variations in Northern hemisphere winter storm track intensity. $J$. Climate, 15, 642-658, doi: 10.1175/1520-0442(2002)0 $15<0642:$ ivinhw $>2.0 . c 0 ; 2$. [Link]

Chen, X. and K.-K. Tung, 2014: Varying planetary heat sink led to global-warming slowdown and acceleration. Science, 345, 897-903, doi: 10.1126/science.1254937. [Link]

Dong, B., R. T. Sutton, T. Woollings, and K. Hodges, 2013: Variability of the North Atlantic summer storm track: Mechanisms and impacts on European climate. Environ. Res. Lett., 8, doi: 10.1088/1748-9326/8/3/034037. [Link]

Enfield, D. B. and A. M. Mestas-Nunez, 1999: Multiscale variabilities in global sea surface temperatures and their relationships with tropospheric climate patterns. J. Climate, 12, 2719-2733, doi: 10.1175/1520-0442(19 99)012<2719:MVIGSS>2.0.CO;2. [Link]

Fraedrich, K., C. Bantzer, and U. Burkhardt, 1993: Winter climate anomalies in Europe and their associated circulation at $500 \mathrm{hPa}$.Clim. Dyn., 8, 161-175, doi: 10.1007/ bf00207963. [Link]

Fyfe, J. C., G. A. Meehl, M. H. England, M. E. Mann, B. D. Santer, G. M.Flato, E. Hawkins, N. P. Gillett, S.-P.Xie, Y. Kosaka, and N. C. Swart, 2016: Making sense of the early-2000s warming slowdown. Nat. Clim. Change, 6, 224-228, doi: 10.1038/nclimate2938. [Link]

Gan, B. and L. Wu, 2015: Feedbacks of Sea Surface Temperature to Wintertime Storm Tracks in the North Atlantic. J. Climate, 28, 306-323, doi: 10.1175/JCLI-
D-13-00719.1. [Link]

Hurrell, J. W., 1995: Decadal trends in the North Atlantic Oscillation: Regional temperatures and precipitation. Science, 269, 676-679, doi: 10.1126/science.269.5224.676. [Link]

Kalnay, E., M. Kanamitsu, R. Kistler, W. Collins, D. Deaven, L. Gandin, M. Iredell, S. Saha, G. White, J. Woollen, Y. Zhu, M. Chelliah, W. Ebisuzaki, W. Higgins, J. Janowiak, K. C. Mo, C. Ropelewski, J. Wang, A. Leetmaa, R. Reynolds, R. Jenne, and D. Joseph, 1996: The NCEP/NCAR 40-Year Reanalysis Project. Bull. Amer. Meteorol. Soc., 77, 437-471, doi: 10.1175/1520-0477( 1996)077<0437:TNYRP>2.0.CO;2. [Link]

Knight, J. R., C. K. Folland, and A. A. Scaife, 2006: Climate impacts of the Atlantic Multidecadal Oscillation. Geophys. Res. Lett., 33, L17706, doi: 10.1029/2006GL026242. [Link]

Kwon, Y.-O. and T. M. Joyce, 2013: Northern Hemisphere winter atmospheric transient eddy heat fluxes and the Gulf Stream and Kuroshio-Oyashio Extension variability. J. Climate, 26, 9839-9859, doi: 10.1175/JCLID-12-00647.1. [Link]

Latif, M., C. Böning, J. Willebrand, A. Biastoch, J. Dengg, N. Keenlyside, U. Schweckendiek, and G. Madec, 2006: Is the Thermohaline Circulation Changing? J. Climate, 19, 4631-4637, doi: 10.1175/JCLI3876.1. [Link]

Lee, S. S., J. Y. Lee, B. Wang, K.-J. Ha, K.-Y. Heo, F.F. Jin, D. M. Straus, and J. Shukla, 2012: Interdecadal changes in the storm track activity over the North Pacific and North Atlantic. Clim. Dyn., 39, 313-327, doi: 10.1007/s00382-011-1188-9. [Link]

Mantua, N. J., S. R. Hare, Y. Zhang, J. M. Wallace, and R. C. Francis, 1997: A Pacific interdecadal climate oscillation with impacts on salmon production. Bull. Amer. Meteorol. Soc., 78, 1069-1079, doi: 10.1175/1520-047 7(1997)078<1069:apicow>2.0.co;2. [Link]

Neu, U., M. G. Akperov, N. Bellenbaum, R. Benestad, R. Blender, R. Caballero, A. Cocozza, H. F. Dacre, Y. Feng, K. Fraedrich, J. Grieger, S. Gulev, J. Hanley, T. Hewson, M. Inatsu, K. Keay, S. F. Kew, I. Kindem, G. C. Leckebusch, M. L. R. Liberato, P. Lionello, I. I. Mokhov, J. G. Pinto, C. C. Raible, M. Reale, I. Rudeva, M. Schuster, I. Simmonds, M. Sinclair, M. Sprenger, N. D. Tilinina, I. F. Trigo, S. Ulbrich, U. Ulbrich, X. L. Wang, and H. Wernli, 2013: IMILAST: A Community Effort to Intercompare Extratropical Cyclone Detection and Tracking Algorithms. Bull. Amer. Meteorol. Soc., 94, 529-547, doi: 10.1175/BAMS-D-11-00154.1. [Link]

Newman, M., G. P. Compo, and M. A. Alexander, 2003: ENSO-forced variability of the Pacific Decadal Oscillation. J. Climate, 16, 3853-3857, doi: 10.1175/1520-0 442(2003)016<3853:evotpd $>2.0 . c o ; 2$. [Link] 
Peings, Y. and G. Magnusdottir, 2014: Forcing of the wintertime atmospheric circulation by the multidecadal fluctuations of the North Atlantic ocean. Environ. Res. Lett., 9, doi: 10.1088/1748-9326/9/3/034018. [Link]

Polonskii, A. B., 2008: Atlantic Multidecadal Oscillation and its manifestations in the Atlantic-European region. Phys. Oceanogr., 18, 227-236, doi: 10.1007/s11110008-9020-8. [Link]

Polonskii, A. B., M. Yu. Bardin, and E. N. Voskresenskaya, 2007: Statistical characteristics of cyclones and anticyclones over the Black Sea in the second half of the 20th century. Phys. Oceanogr., 17, 348-359, doi: 10.1007/ s11110-008-9002-x. [Link]

Power, S., T. Casey, C. Folland, A. Colman, and V. Mehta, 1999: Inter-decadal modulation of the impact of ENSO on Australia. Clim. Dyn., 15, 319-324, doi: 10.1007/ s003820050284. [Link]

Rasmusson, E. G. and T. H. Carpenter, 1982: Variations in tropical sea surface temperature and surface wind fields associated with the Southern Oscillation/El Niño.Mon. Weather Rev., 110, 354-384, doi: 10.1175/1520-0493( 1982) $110<0354:$ vitsst>2.0.co;2. [Link]

Rimbu, N., G. Lohmann, and M. Ionita, 2014: Interannual to multidecadal Euro-Atlantic blocking variability during winter and its relationship with extreme low temperatures in Europe. J. Geophys. Res., 119, 13621-13636, doi: 10.1002/2014JD021983. [Link]

Schlesinger, M. E. and N. Ramankutty, 1994: An oscillation in the global climate system of period $65-70$ years. $\mathrm{Na}$ ture, 367, 723-726, doi: 10.1038/367723a0. [Link]

Semenov, V. A., W. Park, and M. Latif, 2009: Barents Sea inflow shutdown: A new mechanism for rapid climate changes. Geophys. Res. Lett., 36, L14709, doi: 10.1029/2009GL038911. [Link]

Semenov, V. A., I. I. Mokhov, and A. B. Polonsky, 2014: Modeling impact of natural long-term climate variability in the North Atlantic on anomalous weather formation in the Northern hemisphere. Marine Hydrophysical J., 4, 14-27.

Sutton, R. T. and B. Dong, 2012: Atlantic Ocean influence on a shift in European climate in the 1990s. Nat. Geosci., 5, 788-792, doi: 10.1038/ngeo1595. [Link]

Thompson, D. W. J. and J. M. Wallace, 2000: Annular modes in the extratropical circulation. Part 1: Monthto-Month variability. J. Climate, 13, 1000-1016, doi: 10.1175/1520-0442(2000)013<1000:amitec >2.0.co;2 . [Link]

Ting, M., Y. Kushnir, and C. Li, 2014: North Atlantic Multidecadal SST Oscillation: External forcing versus internal variability. J. Mar. Syst., 133, 27-38, doi: 10.1016/j.jmarsys.2013.07.006. [Link]

Trenberth, K. E. and J. T. Fasullo, 2013: An apparent hia- tus in global warming? Earth's Future, 1, 19-32, doi: 10.1002/2013EF000165. [Link]

Trenberth, K. E. and D. J. Shea, 2006: Atlantic hurricanes and natural variability in 2005. Geophys. Res. Lett., 33, L12704, doi: 10.1029/2006GL026894. [Link]

Trenberth, K. E., G. W. Branstator, D. Karoly, A. Kumar, N.-C. Lau, and C. Ropelewski, 1998: Progress during TOGA in understanding and modeling global teleconnections associated with tropical sea surface temperatures. J. Geophys. Res., 103, 14291-14324, doi: 10.1029/97jc01444. [Link]

Trigo, I. F., T. D. Davies, and G. R. Bigg, 1999: Objective climatology of cyclones in the Mediterranean region. J. Climate, 12, 1685-1696, doi: 10.1175/1520-0442(19 99)012<1685:ococit $>2.0 . c 0 ; 2$. [Link]

Tung, K.-K. and J. Zhou, 2013: Using data to attribute episodes of warming and cooling in instrumental records. Proc. Natl. Acad. Sci. USA, 110, 2058-2063, doi: 10.1073/pnas.1212471110. [Link]

Voskresenskaya, E. N. and V. N. Maslova, 2011: Winterspring cyclonic variability in the Mediterranean-Black Sea region associated with global processes in the ocean-atmosphere system. Adv. Sci. Res., 6, 237-243, doi: 10.5194/ASR-6-237-2011. [Link]

Wang, J., B. Yang, F. C. Ljungqvist, and Y. Zhao, 2013: The relationship between the Atlantic Multidecadal Oscillation and temperature variability in China during the last millennium. J. Quat. Sci., 28, 653-658, doi: 10.1002/jqs.2658. [Link]

Wang, X. L., V. R. Swail, and F. W. Zwiers, 2006: Climatology and changes of extratropical cyclone activity: Comparison of ERA-40 with NCEP-NCAR reanalysis for 1958-2001. J. Climate, 19, 3145-3166, doi: 10.1175/jcli3781.1. [Link]

Wolter, K. and M. S. Timlin, 2011: El Niño/Southern Oscillation behaviour since 1871 as diagnosed in an extended multivariate ENSO index (MEI.ext). Intl. J. Climatol., 31, 1074-1087, doi: 10.1002/joc.2336. [Link]

Woollings, T., C. Franzke, and D. L. R. Hodson, B. Dong, E. A. Barnes, C. C. Raible, and J. G. Pinto, 2015: Contrasting interannual and multidecadal NAO variability. Clim. Dyn., 45, 539-556, doi: 10.1007/s00382-0142237-y. [Link]

Wunsch, C., 1999: The Interpretation of Short Climate Records, with Comments on the North Atlantic and Southern Oscillations. Bull. Amer. Meteorol. Soc., 80, 245-255, doi: 10.1175/1520-0477(1999)080<0245:tioscr $>2.0$. co;2. [Link]

Zhang, Y., J. M. Wallace, and D. S. Battisti, 1997: ENSOlike interdecadal variability: 1900-93. J. Climate, 10, 1004-1020, doi: 10.1175/1520-0442(1997)010<1004: eliv>2.0.co;2. [Link] 